\title{
Editorial
}

\section{Saúde, Trabalho e Terapia Ocupacional}

É com satisfação que apresentamos aos leitores este número especial dedicado à área de saúde do trabalhador.

A terapia ocupacional emergiu enquanto profissão justamente relacionada aos problemas de inserção social das pessoas com agravos severos físicos ou mentais e especialmente sua possível inserção no trabalho. Desde então o desafio de compreender o papel do trabalho como principal eixo de contratualidade em nossa sociedade e as práticas de reabilitação ou cuidado que tomam como eixo principal a questão do trabalho tem envolvido grande parte da reflexão e das práticas em nosso campo.

Atualmente os novos ventos da reabilitação psicossocial e o avanço das práticas de desinstitucionalização, passam a reconhecer o direito das populações alvo da atenção e a produção de respostas as suas necessidades como centrais em qualquer processo de cuidado.

Nesse processo, passamos a questionar as velhas estratégias da reabilitação pelo trabalho e buscar novas formas de pensar as relações entre trabalho e reabilitação. Processos de trabalho dotados de sentido para as pessoas e que possam respeitar seus ritmos e desejos e que ao mesmo tempo, sejam capazes de conviver de forma diferente com a diferença e redimensionar as formas da sociedade pensar e agir diante das populações mais vulneráveis, tem preocupado os setores mais comprometidos com a produção de respostas sociais inovadoras, dentro e fora do âmbito específico da profissão.

Nesse mundo em crise e transformações das formas tradicionais de organizar o trabalho se torna fundamental a compreensão e os investimentos dirigidos ao cuidados à saúde e ao aumento do protagonismo social dos trabalhadores vitimados pelo próprio processo de trabalho, nesse contexto a Terapia Ocupacional tem se alinhado com a área de saúde do trabalhador e desenvolvido ações pertinentes aos avanços atuais dessa área.

Neste volume o leitor poderá apreciar alguns pontos de vistas práticos e teóricos que compõe o panorama e desafios desse campo.

Boa leitura!

Elisabete Ferreira Mângia ${ }^{1}$

Selma Lancman ${ }^{1}$

${ }^{1}$ Docentes do Departamento de Fisioterapia, Fonoaudiologia e Terapia Ocupacional da Faculdade de Medicina da Universidade de São Paulo. 